\title{
Particle Swarm Optimization Wavelet Neural Network Of Gearbox
}

\author{
Fault Diagnosis \\ Hanxin Chen ${ }^{1,}$, Liu Yang ${ }^{2, b}$ \\ ${ }^{1,2}$ School of Mechanical and Electrical Engineering,Wuhan Institute of Technology, \\ Wuhan 430074,China. \\ apg01074075@163.com, ${ }^{b}$ wgdyangliu@sina.com
}

Keywords: Particle swarm optimization; Fault diagnosis; Wavelet neural network; Gear crack Abstract: Gear box of the gear crack is the failure forms of gear transmission frequently. Wavelet neural network has the perfect theoretical system, clear the algorithm process, the powerful data identification and simulation function. As traditional gradient descending method of wavelet neural network is easy to fall into local minimum, slow convergence speed and a disadvantage of low efficiency, this article puts forward the particle swarm optimization wavelet neural network learning algorithm. Experiments show that the algorithm optimizes the various parameters of wavelet neural network, reduce the iteration times and improve the convergence precision.

\section{INTRODUCTION}

Classification of gearbox fault diagnosis and state is the necessary measures to ensure the normal operation of equipment. So-called fault diagnosis can be regarded as a kind of pattern recognition, also is the way of using data processing on the state of the gearbox fault classification. Neural network technology is widely applied in the fault state classification, its basic principle is: the obtained after processing after the sampling signal, the response of fault characteristic signal as the network input layer, hidden layer trained after the output of the corresponding output layer, output layer is to identify the fault type of. The process neural network stage need to learn and work, study on neuron weights and threshold of real-time adjustment to match the change of the activation function value, and to determine the revised neural network weights and threshold of. In the process, this article uses the particle swarm optimization training instead of gradient descending method of wavelet neural network and analyzes their features ${ }^{[1]}$.

\section{GEARBOX FAULT DIAGNOSIS TEST}

In order to test this new method for fault diagnosis of gear crack. We simulate a gearbox vibration experiment. There are four conditions, F1 with no fault and F2, F3,F4 with fault. Where F1 is known as gear with no crack in normal condition, and F2, F3, F4 are known as gear with cracks in malfunction.F2, F3, F4 is $1 / 4,1 / 2$ and $3 / 4$ of the full depth and full width respectively. In this test, the gear box is working with load of $100 \%$, at the speed of $800 \mathrm{r} / \mathrm{min}$.

The structure of the gearbox is shown in Fig. 1, gear 3 and 4 will vibrate because of impact, We can choose any of the gears to simulate the malfunction. This experiment select gear 3 . Figure 2 is gear box signal acquisition and analysis system for pictures. Put two acceleration sensors to the gear box in horizontal vertical direction, then use kinetic simulator to collect its vibration signal. And through a spectrum analyzer, the vibration signal was transfered and stored. This paper only 
analysis vibration signal in horizontal direction. Where F1 is stand for signal in normal condition, and F2, F3, F4 is stand for signal in malfunction conditions.

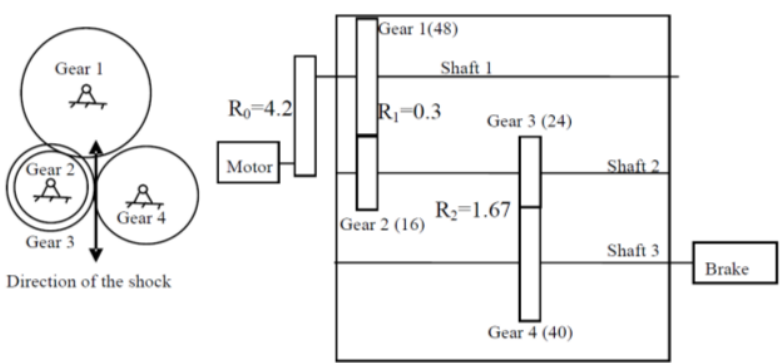

Fig. 1 Structure of the gearbox

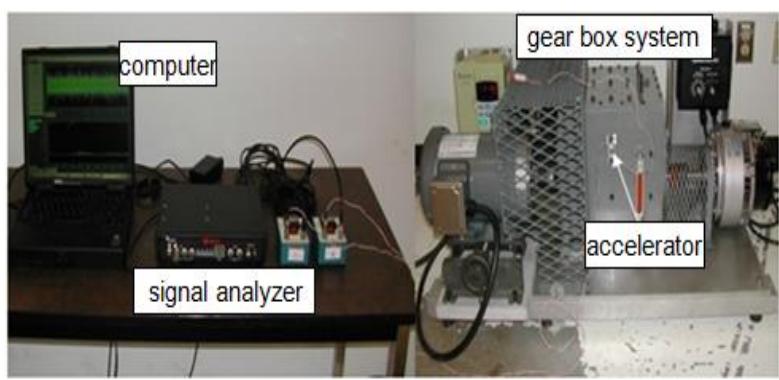

Fig. 2 Gearbox signal acquisition and analysis

\section{PSO WAVELET NEURAL NETWORK TEST GEAR CRACK}

Initialize a group of random particles of particle swarm optimization (pso), also known as random solution. Goal in a $\mathrm{D}$ search space, there are $\mathrm{M}$ particles form a community of $\mathrm{X}, \mathrm{X}$ is expressed as $\mathrm{X}=\left(\mathrm{X}_{1}, \mathrm{X}_{2}, \mathrm{X}_{3} \ldots \mathrm{X}_{\mathrm{M}}\right)$, the case of a particle's current position is expressed as $\mathrm{X}_{i}=$ $\left(\mathrm{X}_{\mathrm{i} 1}, \mathrm{X}_{\mathrm{i} 2} \mathrm{X}_{\mathrm{i} 3 \ldots} \ldots \mathrm{X}_{\mathrm{iD}}\right)$, the case of a particle's speed is expressed as $\stackrel{\mathrm{V}}{\boldsymbol{V}}_{i}=\left(\mathrm{V}_{\mathrm{i} 1}, \mathrm{~V}_{\mathrm{i} 2}, \mathrm{~V}_{\mathrm{i} 3 \ldots} \mathrm{V}_{\mathrm{iD}}\right),(\mathrm{i}=1,2$, $3, \ldots \mathrm{M})$, according to $\stackrel{\mathrm{um}}{X}_{i}$ in the objective function can be concluded that the adaptive value, by the resulting to adapt to the value of the ith a particle current can be determined. The ith particle individual extremum meter for $\mathrm{P}_{\mathrm{i}}=\left(\mathrm{P}_{\mathrm{i} 1}, \mathrm{P}_{\mathrm{i} 2}, \mathrm{P}_{\mathrm{i} 3} \ldots \mathrm{P}_{\mathrm{iD}}\right)$, the whole particle swarm search to group global extremum for $\mathrm{Pg}=\left(\mathrm{Pg}_{1}, \mathrm{Pg}_{2}, \mathrm{Pg}_{3} \ldots \mathrm{Pg}_{\mathrm{D}}\right)$. The basic particle swarm optimization algorithm of updating formula is as follows:

$$
v_{i d}^{k+1}=w v_{i d}^{k}+c_{1} r_{1}\left(p_{i d}^{k}-x_{i d}^{k}\right)+c_{2} r_{2}\left(p_{g d}^{k}-x_{i d}^{k}\right)
$$

$$
x_{i d}^{k+1}=x_{i d}^{k}+v_{i d}^{k+1}
$$

Said the number of iterations of $\mathrm{k}, \mathrm{i}=1,2,3 \ldots \mathrm{M} ; \mathrm{d}=1,2,3 \ldots \mathrm{D} ; \mathrm{c} 1$ and $\mathrm{c} 2$ said acceleration constant, $\mathrm{c} 1$ is adjusting the particle to own the best position of mobile learning factor, c2 is adjusting the particle to the global best position of mobile learning factors.r1, $\mathrm{r} 2$ is independent random numbers between $[0,1], \mathrm{w}$ is the inertia weight factor. $\mathrm{W}_{\max }, \mathrm{w}_{\min }$ are maximum and minimum values of $\mathrm{w}$. Iter and MaxIter are respectively the current iteration number and maximum number of iterations ${ }^{[2-3]}$.Morlet wavelet and Sigmoid function is shown below.

$$
\psi\left(\frac{x-b}{a}\right)=\cos \left(1.75\left(\frac{x-b}{a}\right)\right) \exp \left(-0.5\left(\frac{x-b}{a}\right)^{2}\right)
$$

$$
f(\bullet)=1 / 1+\exp (-x)
$$

Wavelet neural network model as the following .x $1, \mathrm{x} 2, \mathrm{x} 3 \ldots \mathrm{xi}$ is the input layer, $\mathrm{y} 1, \mathrm{y} 2, \mathrm{y} 3 \ldots \mathrm{yn}$ is after network training, the output vector I, J, N is input layer, hidden layer and output layer node number. $\mathrm{w}_{\mathrm{ij}}$ is the weights between input layer and hidden layer, $\mathrm{w}_{\mathrm{jn}}$ is the hidden layer and output layer connection weights, it is input layer to output layer network mapping relationship.

The output of wavelet neural network function is shown below ${ }^{[4]}$.

$$
y_{n}^{p}=f\left[\sum_{j=1}^{J} \omega_{j n} \psi\left(\left(\left(\sum_{i=1}^{I} \omega_{i j} x_{i}^{p}+b 1_{j}\right)-b_{j}\right) / a_{j}\right)+b 2_{n}\right]
$$




$$
E=\frac{1}{N} \sum_{i=1}^{n}\left(D_{i}-Y_{i}\right)^{2}
$$

Define the position of the particle swarm of vector X elements for the connection between the layers of wavelet neural network weights and translation parameters $a$ and $b$ with escalation, the fitness function of wavelet neural network for the mean square error function (6).

Particle swarm optimization algorithm of wavelet neural network as follows:

(1)Set the initial value of the wavelet neural network parameters, scale factor $a$ and $b$ parallel factor, the rest of the network weights of the initial value is set to the random number between the $(0,1)$.

(2)To initialize all parameters of the particle swarm: particle number is set to m, adaptive threshold epsilon, $\mathrm{w}$ maximum minimum set to $\mathrm{W}_{\max }, \mathrm{W}_{\min }$; Accelerating factor set to $\mathrm{c} 1$ and $\mathrm{c} 2$, maximum permissible iteration steps MaxIter; Position of the particle's velocity V, X, initialized to a random number between $(0,1)$.

(3)The particle number $\mathrm{m}$, randomly generated particles group matrix.

(4)Using particle swarm optimization (pso) algorithm in formula (1), (2) of each particle's position $\mathrm{X}$ and velocity $\mathrm{V}$ iteratively update, record the history of each particle optimal position $\mathrm{P}_{\mathrm{id}}$ and yet search to the optimal position of $\mathrm{P}_{\mathrm{gd}}$, fitness value is calculated using the formula (8), and record the corresponding fitness values of $\mathrm{P}_{\text {id }}, \mathrm{P}_{\text {gd }}$ to the FitP $\mathrm{P}_{\text {id }}$ and Fit $\mathrm{P}_{\text {gd }}$.

(5)To determine whether a fitness value to set data, if FitP ${ }_{g d}$ Settings or iterative steps to achieve the maximum set or less iteration steps, then iteration is completed, or go to (3).

(6)Will the value of $\mathrm{P}_{\mathrm{gd}}$ generation into the wavelet neural network scale factor a, translation factor $\mathrm{b}$ and various weights, and calculate the network output ${ }^{[5]}$.

\section{RESULTS AND ANALYSIS}

Through the above experiment collected F1, F2, F3 and F4 these four groups of vibration signal of the data, each data point is 8192 .And then the 8192 data points can be divided into 8 equal segments, each segment is 1024 data points.The corresponding data of the vibration signals after transform to extract the fault characteristic parameters, in this paper, the characteristics of the selected parameters are: average, standard deviation, effective value, peak index and margin index, pulse index, kurtosis index, index of waveform. To collect the data signal is normalized table 1.

After many experiments to compare select neural network structure for the 8-14-4; The number of particle swarm is 40 , the acceleration factor $\mathrm{C} 1=\mathrm{C} 2=2$, the inertial factor $\mathrm{w}$ minimum $\mathrm{w}_{\max }=1.5$ respectively, and the largest $\mathrm{w}_{\min }=0.1$, adaptive threshold epsilon $\varepsilon=0.01$, the particle swarm maximum flying speed for $\mathrm{V}_{\max }=1$; The biggest steps iterative MaxIter $=5000$. 
Table 1 gearbox vibration signal characteristic parameters

\begin{tabular}{ccccccccccc}
\hline \multirow{2}{*}{$\begin{array}{c}\text { Broken } \\
\text { teethsituation }\end{array}$} & The serial & number & $\begin{array}{c}\text { The } \\
\text { mean }\end{array}$ & $\begin{array}{c}\text { Valid } \\
\text { values }\end{array}$ & $\begin{array}{c}\text { Standard } \\
\text { deviateon }\end{array}$ & $\begin{array}{c}\text { Kurtosis } \\
\text { index }\end{array}$ & $\begin{array}{c}\text { Waveform } \\
\text { indicators }\end{array}$ & $\begin{array}{c}\text { Peak } \\
\text { metric }\end{array}$ & $\begin{array}{c}\text { Margin } \\
\text { index }\end{array}$ & $\begin{array}{c}\text { Pulse } \\
\text { index }\end{array}$ \\
\hline No & Trainig & 1 & 0.0778 & 0.0482 & 0.0211 & 0.0605 & 0.0022 & 0.0087 & 0.0073 & 0.0161 \\
crack & Test & 2 & 0.0761 & 0.0481 & 0.0184 & 0.0644 & 0.0023 & 0.0093 & 0.0100 & 0.0174 \\
25\%of & Trainig & 3 & 0.0936 & 0.0651 & 0.0168 & 0.0584 & 0.0037 & 0.0126 & 0.0108 & 0.0158 \\
crack & Test & 4 & 0.0934 & 0.0537 & 0.0187 & 0.0528 & 0.0046 & 0.0120 & 0.0097 & 0.0193 \\
$50 \%$ of & Trainig & 5 & 0.1368 & 0.0162 & 0.0163 & 0.0200 & 0.0018 & 0.0070 & 0.0088 & 0.0108 \\
crack & Test & 6 & 0.1420 & 0.0179 & 0.0097 & 0.0178 & 0.0017 & 0.0065 & 0.0082 & 0.0087 \\
$75 \%$ of & Trainig & 7 & 1.0484 & 0.0392 & 0.0274 & 0.0519 & 0.0053 & 0.0101 & 0.0089 & 0.0185 \\
crack & Test & 8 & 0.9969 & 0.0456 & 0.0265 & 0.0588 & 0.0042 & 0.0098 & 0.0122 & 0.0186 \\
\hline
\end{tabular}

Will the 8 groups of the training sample in table 2 wavelet neural network was trained by particle swarm optimization.

Figure 3 is wavelet neural network evolution curve, Figure 4 is particle swarm optimization wavelet neural network evolution curve. The horizontal axis is the number of iterations, $y$ coordinate is the average error value. See from the diagram of the wavelet neural network, 5000 iterations mean error of wavelet neural network is 2.97. The particle swarm optimization wavelet neural network of 1536 iterations have reached to the average error of 0.01 requirements, but also it can be seen after 600 iterations when error of the mean value is 0.86 . The speed of convergence is faster.

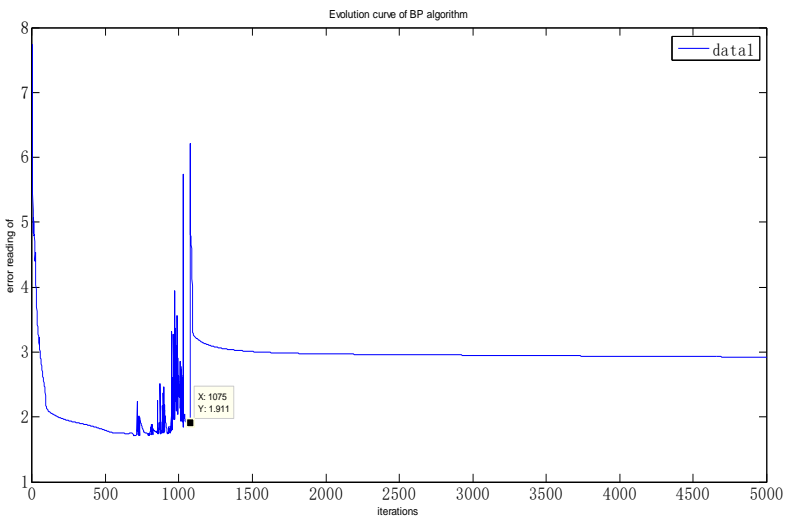

Fig.3 wavelet neural network evolution curve

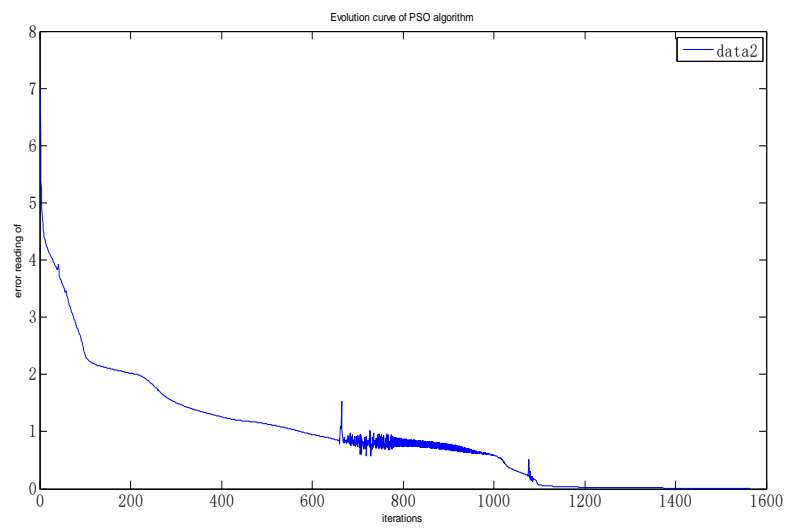

Fig.4 curve evolution pso wavelet neural network

The input a set of test samples after training of wavelet neural network and particle swarm optimization diagnosis results are shown in table 2 below.

Table 2 test sample output and diagnosis

\begin{tabular}{cccccc}
\hline number & \multicolumn{5}{c}{ Check the output } \\
\hline 2 & 0.9642 & 0.0543 & 0.0153 & 0.0046 & The diagnosis \\
4 & 0.0214 & 0.9557 & 0.0052 & 0.0103 & $25 \%$ of crack \\
6 & 0.0210 & 0.0007 & 0.9453 & 0.0121 & $50 \%$ of crack \\
8 & 0.0004 & 0.0324 & 0.0047 & 0.9975 & $75 \%$ of crack \\
\hline
\end{tabular}

\section{CONCLUSION}

Experiments show that wavelet neural network by using particle swarm optimization for gear crack fault diagnosis of gearbox is able to accurately identify the damage of the crack. Particle swarm optimization algorithm is compared with the traditional gradient descending method, 
reduced the number of iterations, the error precision is improved. This method can be found in the earlier in the process of gear transmission gear crack damage, for the whole of the gear transmission system overhaul scheme provides a good guidance and reference.

\section{ACKNOWLEDGEMENT}

The project is supported by the National Natural Science Foundation of China (Grant no.612731 76), Major project of Hubei Provincial Department of Education (Z20101501) and Scientific Resea rch Foundation for the Returned Overseas Chinese Scholars, State Education Ministry(20091001)

\section{REFERENCES}

[1]Wang Zemin. the gear and rolling bearing fault feature separation method research [D]. Taiyuan, taiyuan university of technology, 2010

[2]Kennedy J,Eberhart R. Particle swarm optimization[A].in:Proceedings of the 4th IEEE International Conference on Neural Networks[C],Piscataway:

IEEE Service Center,1995,pp.1942-1948.

[3]Simon Garnier,Jacques Gautrais,Guy Theraulaz.The biological principles of swarm intelligence[J].Swarm Intelligence,no.1,pp.3-31,2007.

[4] xue-zhi zhao. Knit primavera, etc.Initial parameters of wavelet neural network optimization study [J]. Journal of south China university of technology (natural science edition), 2003, 31 (2) : $77-84$

[5]K.Parsopoulos and M. Vrahatis,Recent approaches to global optimization problems through particle swarm optimization[J].Natural Computing,vol.1,pp.235-306,May 2002. 